\title{
Rapid Quantitative Evaluation of Amphotericin B in Human Plasma, by Validated HPLC Method
}

\author{
Pavan Balabathula ${ }^{1 *}$, Dileep R Janagam², Nivesh K Mittal' ${ }^{1}$, Bivash Mandal ${ }^{1}$, Laura A Thoma ${ }^{1}$ and George C Wood \\ ${ }^{1}$ Plough Center for Sterile Drug Delivery Systems, Department of Pharmaceutical Sciences, College of Pharmacy, University of Tennessee Health Science Center, \\ Memphis, TN, USA \\ ${ }^{2}$ Department of Pharmaceutical Sciences, College of Pharmacy, University of Tennessee Health Science Center, Memphis, TN, USA
}

\begin{abstract}
A simple, rapid, and sensitive HPLC method was developed and validated to quantify Amphotericin B (AmB) in human plasma. AmB was extracted from spiked plasma by simple protein precipitation with methanol. The separation was performed on an XBridge ${ }^{\mathrm{TM}} \mathrm{C} 18(150 \times 4.6 \mathrm{~mm}, 3.5 \mu \mathrm{m})$ column, with a mobile phase of acetic acid $(0.73 \%)$ - acetonitrile $(60: 40, \mathrm{v} / \mathrm{v})$ and at a flow rate of $1 \mathrm{~mL} / \mathrm{min}$. The eluted peak of AmB was monitored at $408 \mathrm{~nm}$ with photo-diode array detector (PDA) detector. The calibration curve was found linear in the AmB concentration range of $1000-50 \mathrm{ng} / \mathrm{mL}\left(\mathrm{r}^{2}>0.99\right)$. The inter- and intra-day precisions $(\% \mathrm{CV})$ were less than $11.2 \%$. The extraction recoveries were $85-91 \%$. The method developed and validated is simple, rapid ( $<3$ min per injection), sensitive, and reproducible. It potentially can be used for the pharmacokinetic, bioequivalence, and toxicokinetic studies of AmB.
\end{abstract}

Keywords: Amphotericin B; HPLC; Method development; Validation; Extraction; Human plasma

\section{Introduction}

Amphotericin B (AmB), an amphipathic fermentation compound produced by the South American soil gram positive bacterium Streptomyces nodosus and is considered as a gold standard for treating severe systemic fungal infections. Long-term usage of $\mathrm{AmB}$ leads to high incidence of adverse effects, predominantly nephrotoxicity and infusion-related toxicity. However, several formulations of $\mathrm{AmB}$ were developed to reduce the toxicity and to improve the therapeutic efficacy, they still cause considerable amount of toxicity [1,2]. Hence, a careful monitoring of patients under treatment with $\mathrm{AmB}$ is required and demands for a simple, rapid, sensitive, and inexpensive method to determine $A m B$ in biological samples like plasma and there by determine its pharmacokinetic, bioequivalence, and toxicokinetic profile.

Several analytical methods have been reported for the determination of $\mathrm{AmB}$ in biological samples like plasma using high pressure liquid chromatography (HPLC) [3-16]. However, some of the reported HPLC methods have used salts in their mobile phase $[7,12,13]$, which lowers the life-time of the column by significantly increasing the risk of saturation, breakdown or over pressure in the column. Longer retention times in a few reported methods $[4,8,9,15]$ require more time to analyze the samples and also consume more solvents. Though a reported method indicated short retention time for the elution of $\mathrm{AmB}$, the peak resolution and symmetry is questionable [6].

The aim of this study was to develop and validate a simple, rapid, sensitive and reproducible isocratic HPLC method with a well resolved symmetrical peak of interest for the estimation of $\mathrm{AmB}$ in plasma samples. This method can be easily established in research and clinical laboratories for analyzing large number of plasma samples obtained for pharmacokinetic, bioequivalence or toxicokinetic studies after administration of AmB.

\section{Materials and Methods}

\section{Reagents and chemicals}

AmB USP analytical sample standard was obtained from MP
Biomedicals (Santa Ana, CA, USA) and HPLC grade methanol, acetonitrile, dimethyl sulfoxide (DMSO), acetic acid and water were obtained from Fisher (Pittsburg, PA, USA). Drug-free human plasma was purchased from Innovative Research (Novi, MI, USA).

\section{Instrumentation}

All chromatographic studies were conducted on validated and qualified equipment. Chromatography was performed with a Waters HPLC Alliance system on an e2695 separations module with a Waters 2998 photo-diode array (PDA) detector (Milford, MA, USA). Samples were injected using a Waters auto injector and the instrument was controlled by use of Empower2 ${ }^{\circledR}$ software (Milford, MA, USA). Components were separated on a Waters XBridge ${ }^{\mathrm{TM}} \mathrm{C} 18$ reversedphase column (Milford, MA, USA) with $150 \mathrm{~mm}$ X $4.6 \mathrm{~mm}$ dimensions and $3.5 \mu \mathrm{m}$ particle size. The column was kept thermostatic at $30^{\circ} \mathrm{C}$ in a Waters column oven (Milford, MA, USA).

\section{Chromatographic conditions}

The developed method used for detection and quantification of $\mathrm{AmB}$ was an isocratic method using an $\mathrm{XBridge}^{\mathrm{TM}} \mathrm{C} 18$ reversed-phase column with a mobile phase of acetic acid $(0.73 \%)$-acetonitrile $(60: 40$, $\mathrm{v} / \mathrm{v})$. The flow rate of the solvent was $1.0 \mathrm{~mL} / \mathrm{min}$ with a runtime of 6 minutes. Samples were injected into the column at a constant volume of $20 \mu \mathrm{L}$ and a PDA detector at $408 \mathrm{~nm}$ was employed to obtain the responses of varied concentrations of $\mathrm{AmB}$. The column was maintained at $30^{\circ} \mathrm{C}$.

\section{Statistical methods}

Standard calibration curves were plotted using peak areas and

*Corresponding author: Pavan Balabathula, 26 S Dunlap St. Suite 214 Memphis TN - 38163, USA, Tel: +001-901-448-4637; Fax: +001-901-448-6092; E-mail pbalabat@uthsc.edu

Received April 04, 2013; Accepted April 27, 2013; Published May 03, 2013

Citation: Balabathula P, Janagam DR, Mittal NK, Mandal B, Thoma LA, et al (2013) Rapid Quantitative Evaluation of Amphotericin B in Human Plasma, by Validated HPLC Method. J Bioequiv Availab 5: 121-124. doi:10.4172/jbb.1000145

Copyright: (c) 2013 Balabathula P, et al. This is an open-access article distributed under the terms of the Creative Commons Attribution License, which permits unrestricted use, distribution, and reproduction in any medium, provided the original author and source are credited. 
Citation: Balabathula P, Janagam DR, Mittal NK, Mandal B, Thoma LA, et al. (2013) Rapid Quantitative Evaluation of Amphotericin B in Human Plasma, by Validated HPLC Method. J Bioequiv Availab 5: 121-124. doi:10.4172/jbb.1000145

concentrations of the standard solutions. The data were fit to a linear model using a least squares regression analysis. The back calculated concentrations of the standards and the plasma samples (calculated using regression line) were used to determine the means, standard deviations (SD), and \% coefficients of variation $(\% \mathrm{CV})$ at each concentration.

\section{Preparation of standards for calibration curve}

$\mathrm{AmB}$ stock solutions were prepared each day of analysis, by dissolving an accurate amount of USP standard AmB in the mixture of HPLC grade DMSO-methanol (50:50, v/v). The standard concentrations of $1000,800,600,400,200,100$, and $50 \mathrm{ng} / \mathrm{mL}$ were prepared by serial dilution in HPLC grade methanol. Each standard solution was injected $(20 \mu \mathrm{L} /$ injection) in sextuplicate and chromatographed under the described conditions. The method developed for the analysis of AmB was validated by developing a standard calibration curve with the standard concentrations on three different days. A different stock solution prepared each day, respectively. The following parameters were calculated for the validation of the AmB assay; linearity, accuracy, intra-day and inter-day precision, limit of detection (LOD), and limit of quantification (LOQ).

\section{Method for determining linearity and accuracy}

The standard dilutions of $\mathrm{AmB}(1000-50 \mathrm{ng} / \mathrm{mL})$ were injected in series and the peak area responses were recorded. The standard concentrations were plotted against each peak area. A line of least squares regression was constructed, the slope and intercept were calculated and the coefficient of determination was determined for each calibration curve. Accuracy was determined by quantifying standard solutions in sextuplicate followed by the determination of the mean and \% nominal.

\section{Ruggedness}

Ruggedness of the method developed is evaluated by testing the reproducibility of the $\mathrm{AmB}$ peak resolution and its retention time obtained under a variety of normal test conditions, such as different laboratory, different analyst, different instruments, different lots of reagents, and different days.

\section{Method for determining precision, LOD, and LOQ}

Precision was calculated in accordance with International Conference on Harmonisation (ICH) guidelines for both repeatability and intermediate precision [17]. R -Galera et al. [6]. Human plasma samples (100 epeatability of the method was determined as intra-day variation and intermediate precision of the assay was determined by inter-day variation $[18,19]$. In order to determine both the intra-day and inter-day precision, $\mathrm{AmB}$ solutions at six different concentrations $(1000,800,400,200,100$, and $50 \mathrm{ng} / \mathrm{mL})$ were determined in sextuplicate and mean and \% CV were calculated. LOD and LOQ were determined by applying the following formula [20];

$$
\begin{aligned}
& L O D=3.3 \sigma / m \\
& L O Q=10 \sigma / m
\end{aligned}
$$

Where, $\sigma$ is the standard deviation of the intercept of regression line, and $m$ is the slope of the calibration curve.

\section{Plasma extraction and preparation of the samples}

The method of extraction was adapted from previously reported protocol by Lopez-Galera et al. [6]. Human plasma samples (100 $\mu \mathrm{L})$ were spiked with $\mathrm{AmB}$ solution $(20 \mu \mathrm{L})$ to obtain the plasma concentrations of $5,2,1$, and $0.5 \mu \mathrm{g} / \mathrm{mL}$ and incubated at ambient temperature for $10 \mathrm{~min}$. Spiked drug was extracted by adding $680 \mu \mathrm{L}$ of methanol to spiked plasma samples, vortex for 30 secs and sonicated for 3 minutes. The samples were then centrifuged at $20000 \mathrm{~g}$ for $5 \mathrm{~min}$ at $4^{\circ} \mathrm{C}$ and supernatant was assayed for recovery of $\mathrm{AmB}$ in triplicates by using validated HPLC assay. A control sample of plasma was prepared in the similar way but without adding AmB.

\section{Results and Discussion}

\section{HPLC method development}

An HPLC method was developed to measure AmB concentrations from 1000 to $50 \mathrm{ng} / \mathrm{mL}$ in plasma samples by using $\mathrm{XBridge}^{\mathrm{TM}} \mathrm{C} 18$ column and simple mobile phase. Different flow-rates and ratios of the mobile phase were studied in order to obtain a well resolved symmetrical AmB peak with a shorter retention time. The optimal separation was obtained with a mobile phase of acetic acid (0.73\%)-acetonitrile (60:40, $\mathrm{v} / \mathrm{v}$ ) and with a flow-rate of $1 \mathrm{~mL} / \mathrm{min}$. The $\mathrm{AmB}$ peak in the standard solutions indicated a baseline separation with a retention time of approximately 2.7 minutes. The suitability of the method for analysis of $\mathrm{AmB}$ was confirmed by analysis of $\mathrm{AmB}$ concentration in each spiked plasma sample. Example chromatograms obtained for drug-free human plasma and AmB spiked human plasma are shown in figure 1.

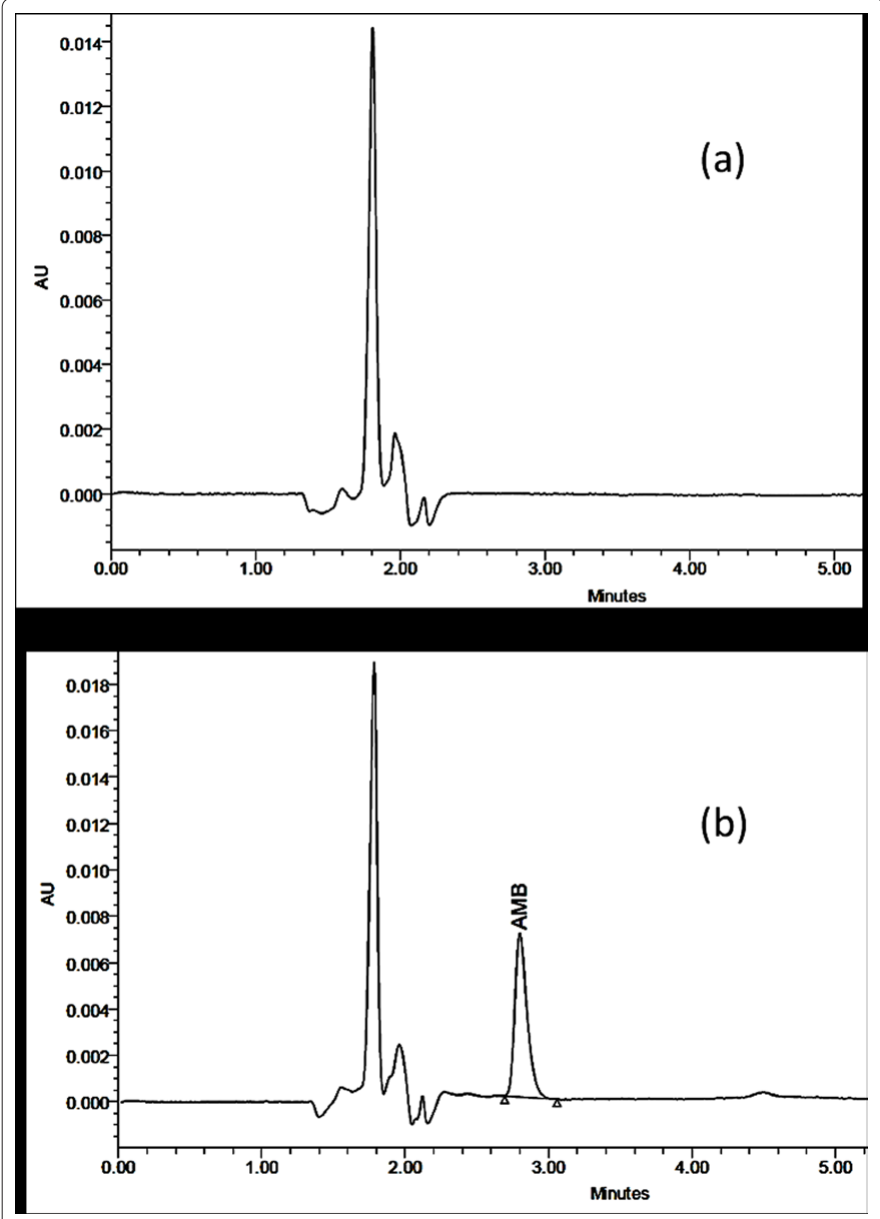

Figure 1: A representative chromatograms of drug-free plasma (a) and AmB spiked human plasma $(b)$, retention time $\left(t_{R}\right)=2.7$ minutes. 
Citation: Balabathula P, Janagam DR, Mittal NK, Mandal B, Thoma LA, et al. (2013) Rapid Quantitative Evaluation of Amphotericin B in Human Plasma, by Validated HPLC Method. J Bioequiv Availab 5: 121-124. doi:10.4172/jbb.1000145

No other peak is eluted with retention time similar to AmB in blank human plasma.

\section{Linearity \& accuracy}

The linearity of the peak area versus the concentration (amount) was studied in the range of $1000-50 \mathrm{ng} / \mathrm{mL}$ for $\mathrm{AmB}$ and the results were subjected to statistical analysis using a linear-regression leastsquares method. The linear regression data for the calibration curve, as shown in the table 1, is indicative of a significant linear relationship between amount and peak area over the range studied. The calibration curves were found to be linear with a correlation coefficient $\left(\mathrm{r}^{2}\right)$ of 0.9964-0.9999. There were no significant inter-day differences between the slopes of the calibration curves. The low values of the standard deviation and standard error of slope indicates lack of deviation from the linearity or analytical bias in the calibration curve.

The accuracy of the method was determined by calculating the mean concentrations and \% nominal mean for concentrations 1000 to $50 \mathrm{ng} / \mathrm{mL}$ for the three standard curves of $\mathrm{AmB}$ (Table 2). The \% nominal mean (93.9-111.61\%) indicate the method is acceptably accurate.

\section{Precision, LOD \& LOQ}

Precision was determined, as both repeatability and intermediate precision, in accordance with ICH recommendations. Repeatability of the method was determined as intra-day variation, and intermediate precision was calculated by determining inter-day variation for sextuplicate determinations of $\mathrm{AmB}$ at six different concentrations

\begin{tabular}{|l|l|}
\hline Linearity range $(\mathrm{ng} / \mathrm{mL})$ & $50-1000$ \\
\hline Regression equation & $\mathrm{y}=129.33 \mathrm{x}-1050.83$ \\
\hline Correlation coefficient $\left(\mathrm{r}^{2}\right) \pm \mathrm{SD}$ & $0.9981 \pm 0.0018$ \\
\hline Slope $\pm \mathrm{SD}$ & $129.33 \pm 4.04$ \\
\hline Standard error of slope & 2.33 \\
\hline
\end{tabular}

Table 1: Linear regression data for calibration curve $(n=3)$.

\begin{tabular}{|c|c|c|c|c|c|}
\hline Days & $\begin{array}{c}\text { Actual } \\
\text { Conc. }(\mathbf{n g} / \\
\mathbf{m L})\end{array}$ & $\begin{array}{c}\text { Mean Conc. } \\
\mathbf{( n g / m L})\end{array}$ & $\begin{array}{c}\text { Standard } \\
\text { Deviation }\end{array}$ & $\begin{array}{c}\text { Nominal } \\
\mathbf{( \% )}\end{array}$ & $\begin{array}{c}\text { CV } \\
\mathbf{( \% )}\end{array}$ \\
\hline 1 & 50 & 52.385 & 1.48 & 104.77 & 2.82 \\
\hline 2 & 50 & 46.949 & 1.16 & 93.9 & 2.48 \\
\hline 3 & 50 & 60.806 & 0.85 & 111.61 & 1.39 \\
\hline 1 & 100 & 101.626 & 0.98 & 101.63 & 0.96 \\
\hline 2 & 100 & 90.363 & 1.5 & 99.36 & 1.66 \\
\hline 3 & 100 & 109.939 & 1.32 & 109.94 & 1.2 \\
\hline 1 & 200 & 196.742 & 0.85 & 98.37 & 0.43 \\
\hline 2 & 200 & 198.633 & 1.3 & 99.32 & 0.66 \\
\hline 3 & 200 & 192.351 & 1.97 & 96.18 & 1.02 \\
\hline 1 & 400 & 399.164 & 1.47 & 99.79 & 0.37 \\
\hline 2 & 400 & 408.131 & 1.83 & 102.03 & 0.45 \\
\hline 3 & 400 & 385.919 & 2.42 & 96.48 & 0.63 \\
\hline 1 & 800 & 796.896 & 2.07 & 99.61 & 0.26 \\
\hline 2 & 800 & 838.937 & 2.82 & 104.87 & 0.34 \\
\hline 3 & 800 & 776.791 & 3.69 & 97.1 & 0.47 \\
\hline 1 & 1000 & 1003.187 & 5.57 & 100.32 & 0.56 \\
\hline 2 & 1000 & 966.989 & 3.94 & 96.7 & 0.41 \\
\hline 3 & 1000 & 1024.862 & 2.64 & 102.42 & 0.26 \\
\hline
\end{tabular}

Table 2: Accuracy and intra-day precision of the method for the determination of $\operatorname{AmB}(n=6)$.

\begin{tabular}{|c|c|c|}
\hline Actual conc. (ng/mL) & $\begin{array}{c}\text { Mean Conc. }(\mathbf{n g} / \mathbf{m L}) \\
(\boldsymbol{n = 1 8})\end{array}$ & $\begin{array}{c}\text { CV } \\
(\%)\end{array}$ \\
\hline 50 & 53.380 & 11.19 \\
\hline 100 & 100.642 & 8.29 \\
\hline 200 & 195.908 & 1.55 \\
\hline 400 & 397.738 & 2.40 \\
\hline 800 & 804.208 & 3.33 \\
\hline 1000 & 998.124 & 2.47 \\
\hline
\end{tabular}

Table 3: Inter-day variability of the method for the determination of AmB.

\begin{tabular}{|c|c|c|c|c|}
\hline $\begin{array}{c}\text { Plasma Conc. } \\
(\boldsymbol{\mu g} / \mathbf{m L})\end{array}$ & $\begin{array}{l}\text { Spiked } \\
(\mathbf{n g})\end{array}$ & Found $(\mathbf{n g})$ & $\begin{array}{c}\text { \%Recovery } \\
(\mathbf{m e a n} \pm \mathbf{S D})\end{array}$ & CV (\%) \\
\hline 5 & 600 & 535.38 & $89.23 \pm 1.88$ & 0.27 \\
\hline 2 & 240 & 204.528 & $85.22 \pm 2.37$ & 0.90 \\
\hline 1 & 120 & 105.132 & $87.61 \pm 0.52$ & 0.39 \\
\hline 0.5 & 60 & 54.768 & $91.28 \pm 1.47$ & 1.90 \\
\hline
\end{tabular}

Table 4: Accuracy and recovery of AmB in spiked human plasma $(n=3)$.

( 1000 and $50 \mathrm{ng} / \mathrm{mL}$ ) on three different days for three calibration curves. Calculated values of mean and \%CV for determination of repeatability and intermediate precision are listed in tables 2 and 3 . The low values of $\% \mathrm{CV}$ indicate the acceptable repeatability and intermediate precision of the method. The LOD and LOQ of AmB of the developed method were found to be 9.98 and $29.97 \mathrm{ng} / \mathrm{mL}$, respectively. This sensitivity is achieved with just $20 \mu \mathrm{L}$ of injection volume and can be improved with higher injection volumes.

\section{Ruggedness}

Under a variety of normal test conditions as mentioned in the methods section, the AmB peak was found to be well resolved from all other peaks with the retention time of 2.7 minutes, illustrating the ruggedness of the method.

\section{Recovery}

Mean recovery of AmB from human plasma was found to be $88 \%$ at concentrations of 500 to $5000 \mathrm{ng} / \mathrm{mL}$. Recoveries and the accuracy of the assay in determining $\mathrm{AmB}$ in spiked human plasma samples are summarized in table 4 . The deviation from theoretical values is under $15 \%$ at all concentrations levels studied.

\section{Conclusion}

A validated isocratic HPLC method has been developed for the determination of $\mathrm{AmB}$ in human plasma samples. The method is simple, rapid, accurate, and precise. Additionally, relatively shorter retention times ( $<3$ min per injection) of $\mathrm{AmB}$ allow the analysis of a large number of samples in a short period of time. Therefore, this rapid and inexpensive method should be suitable for the routine analysis of AmB in clinical settings and to evaluate its pharmacokinetic, bioequivalence, and toxicokinetic profile.

\section{References}

1. Cleary JD, Rogers PD, Chapman SW (2003) Variability in polyene conten and cellular toxicity among deoxycholate amphotericin B formulations. Pharmacotherapy 23: 572-578.

2. Zaragoza R, Peman J (2008) The diagnostic and therapeutic approach to fungal infections in critical care settings. Advances in Sepsis 6: 90-98. 
Citation: Balabathula P, Janagam DR, Mittal NK, Mandal B, Thoma LA, et al. (2013) Rapid Quantitative Evaluation of Amphotericin B in Human Plasma, by Validated HPLC Method. J Bioequiv Availab 5: 121-124. doi:10.4172/jbb.1000145

3. Nilsson-Ehle I, Yoshikawa TT, Edwards JE, Schotz MC, Guze LB (1977) Quantitation of amphotericin B with use of high-pressure liquid chromatography. J Infect Dis 135: 414-422.

4. Granich GG, Kobayashi GS, Krogstad DJ (1986) Sensitive high-pressure liquid chromatographic assay for amphotericin B which incorporates an internal standard. Antimicrob Agents Chemother 29: 584-588

5. Hulsewede JW, Dermoumi H (1994) Comparison of high-performance liquid chromatography and bioassay of amphotericin B in serum. Mycoses 37: 17-21.

6. Lopez-Galera R, Pou-Clave L, Pascual-Mostaza C (1995) Determination of amphotericin $B$ in human serum by liquid chromatography. J Chromatogr $B$ Biomed Appl 674: 298-300

7. Alak A, Moy S, Bekersky I (1996) A high-performance liquid chromatographic assay for the determination of amphotericin $B$ serum concentrations after the administration of AmBisome, a liposomal amphotericin B formulation. Ther Drug Monit 18: 604-609.

8. Ng TK, Chan RC, Adeyemi-Doro FA, Cheung SW, Cheng AF (1996) Rapid high performance liquid chromatographic assay for antifungal agents in human sera. J Antimicrob Chemother 37: 465-472.

9. Lambros MP, Abbas SA, Bourne DW (1996) New high-performance liquid chromatographic method for amphotericin B analysis using an internal standard. J Chromatogr B Biomed Appl 685: 135-140.

10. Campanero M, Zamarreno A, Diaz M, Dios-Vieitez M, Azanza J (1997) Development and validation of an HPLC method for determination of amphotericin $\mathrm{B}$ in plasma and sputum involving solid phase extraction. Chromatographia 46: 641-646.

11. Echevarria I, Barturen C, Renedo MJ, Dios-Vieitez MC (1998) Highperformance liquid chromatographic determination of amphotericin B in plasma and tissue. Application to pharmacokinetic and tissue distribution studies in rats. J Chromatogr A 819: 171-176.

12. Egger P, Bellmann R, Wiedermann CJ (2001) Determination of amphotericin
B, liposomal amphotericin B, and amphotericin B colloidal dispersion in plasma by high-performance liquid chromatography. J Chromatogr B Biomed Sci App 760: 307-313.

13. Eldem T, Arican-Cellat N (2001) Determination of amphotericin B in human plasma using solid-phase extraction and high-performance liquid chromatography. J Pharm Biomed Anal 25: 53-64.

14. Bekersky I, Fielding RM, Dressler DE, Lee JW, Buell DN, et al. (2002) Pharmacokinetics, excretion, and mass balance of liposomal amphotericin $B$ (AmBisome) and amphotericin B deoxycholate in humans. Antimicrob Agents Chemother 46: 828-833.

15. Espada R, Josa JM, Valdespina S, Dea MA, Ballesteros MP, et al. (2008) HPLC assay for determination of amphotericin B in biological samples. Biomed Chromatogr 22: 402-407.

16. Italia JL, Singh D, Ravi Kumar MN (2009) High-performance liquid chromatographic analysis of amphotericin $B$ in rat plasma using alpha-naphthol as an internal standard. Anal Chim Acta 634: 110-114.

17. Food and Drug Administration (1996) International Conference on Harmonisation: guidance on Q2(R1) validation of analytical procedures: text and methodology. Fed Regist 62: FR 27464.

18. Jamalapuram S, Vuppala PK, Mesangeau C, McCurdy CR, Avery BA (2012) Determination of a highly selective mixed-affinity sigma receptor ligand, in rat plasma by ultra performance liquid chromatography mass spectrometry and its application to a pharmacokinetic study. J Chromatogr B Analyt Technol Biomed Life Sci 891-892: 1-6.

19. Vuppala PK, Boddu SP, Furr EB, McCurdy CR, Avery BA (2011) Simple, sensitive, high-throughput method for the quantification of mitragynine in rat plasma using UPLC-MS and its application to an intravenous pharmacokinetic study. Chromatographia 74: 703-710

20. Mandal B, Balabathula P, Mittal N, Wood GC, Bhattacharjee H (2012) Development and validation of a spectrofluorimetric method for the determination of erlotinib in spiked human plasma. J Fluoresc 22: 1425-1429. 